\title{
REVENDO O CÂNONE HEGEMÔNICO DA HISTÓRIA DAS TEORIAS DE TRADUÇÃO: O PIONEIRISMO DE D. DUARTE, REI DE PORTUGAL
}

\author{
Cristina de Amorim Machado \\ Pontifícia Universidade Católica-Rio \\ cristina_machado@yahoo.com \\ Marcia A. P. Martins \\ Pontifícia Universidade Católica-Rio \\ mmartins@puc-rio.br
}

\begin{abstract}
Resumo: O objetivo deste trabalho é contribuir para uma expansão do corpus das primeiras teorizações sobre tradução por meio da apresentação e análise do texto "Da maneira pera bem tornar algũa leitura em nossa linguagem", de autoria de D. Duarte, rei de Portugal (1433-1438). Nos parágrafos iniciais do texto, que integra sua obra Leal conselheiro, escrita entre 1435 e 1438, D. Duarte formula cinco regras para se fazer uma boa tradução para o português e em seguida elabora comentários sobre dois exemplos de traduções realizadas por ele: uma oração em latim do século $\mathrm{X}$ e um fragmento de capítulo de livro. Pretende-se, assim, chamar a atenção dos historiadores da tradução para as reflexões produzidas em línguas e culturas não hegemônicas, mesmo que europeias, como é o caso de Portugal, que não costumam ser incluídas nas antologias que contemplam essas primeiras teorizações.
\end{abstract}

Palavras-chave: teorias de tradução, D. Duarte I de Portugal, língua portuguesa, Renascimento.

Abstract: The purpose of this article is to contribute to an expansion of the corpus of early translation theory by presenting and analyzing the text "Da maneira pera bem tornar algua leitura em nossa linguagem" [How to make a good translation of a text into our language] by Dom Duarte, king 
of Portugal (1433-1438). In the opening paragraphs of the text, which is part of his work Leal conselheiro (written between 1435 and 1438), Dom Duarte proposes five rules for good translation into Portuguese and comments on two translations he has made: a Latin prayer from the 10th century and an excerpt from a book chapter. The aim is to call the attention of historians of translation to the ideas produced in languages and cultures that are non-hegemonic, even if European, as is the case of Portugal, and are not usually included in anthologies of early translation theories.

Keywords: translation theories, King Duarte of Portugal, Portuguese language, Renaissance.

Pouco se tem falado sobre a história das teorias de tradução produzidas em países de língua portuguesa; de maneira geral, os holofotes se voltam para outras geografias. No entanto, depois de cerca de quinhentos anos de dominação árabe, o século XII testemunhou o florescimento da escrita no idioma hoje conhecido como português europeu, que começava sua história emancipada do latim. Dentre as primeiras produções escritas em língua portuguesa, além de cartas reais e documentos oficiais, destacam-se traduções e - o que mais nos interessa aqui - algumas teorizações sobre tradução. Esse pioneirismo português não costuma ser registrado em volumes sobre a história das teorias de tradução ou nas ainda poucas antologias ou congêneres publicadas por grandes editoras internacionais que reúnem teorizações importantes ou seminais (Bassnett, 1980; Ballard, 1992; Rener, 1989). A única exceção é a coletânea organizada por Douglas Robinson, Western translation theory: from Herodotus to Nietzsche (1997), que inclui um pequeno fragmento, traduzido para o inglês, da reflexão de D. Duarte, rei de Portugal no século XV, que será examinada neste trabalho.

Em Portugal, por sua vez, encontramos duas antologias de teorizações que evidentemente mencionam e analisam, entre outros, o pioneiro texto de D. Duarte, intitulado "Da maneira pera bem tornar algũa leitura em nossa linguagem” (Anexo I). São elas: Teoria diacrónica da tradução portuguesa: antologia (séculos $X V-X X)$, de Carlos Castilho Pais (1997), e $O$ discurso sobre a tradução em Portugal, de José Antonio Sabio Pinilla e María Manuela Fernán- 
dez Sánchez (1998). No entanto é somente num artigo espanhol, "Humanismo renascentista y la traducción en Portugal (siglos XVI y XVII)”, de 2003, dos mesmos Pinilla \& Sánchez, que encontramos uma elaboração um pouco mais ambiciosa, ainda que breve, a "uma das primeiras reflexões teóricas sobre a tradução não só em Portugal, mas em toda a Europa" (Pinilla \& Sánchez, 2003: 208). No Brasil, a "Brevíssima história da teoria da tradução no Ocidente", de Mauri Furlan (2004), ressalta que uma das características da história da tradução renascentista é "o desenvolvimento de reflexões teóricas sobre a prática tradutora, que se apresentam geralmente sob a forma de pequenos textos, cartas, introduções, tratados etc." (p. 21) e relaciona textos importantes produzidos nesse período na Itália, França, Espanha e Grã-Bretanha, "países onde a atividade da tradução e sua reflexão se destacaram" (p. 21), não havendo menção a produções em língua portuguesa. Já no volume 4 da antologia bilíngue Clássicos da Teoria da Tradução, dedicado ao Renascimento (Furlan, 2006), o organizador inclui um excerto do "Diálogo em louvor da nossa linguagem", do gramático e "proto-linguista" português João de Barros (1496-1570), que destaca qualidades da língua portuguesa, como a versatilidade e capacidade de expressão, e revela "uma concepção de tradução que enriquece a língua de chegada, a respeita e pode torná-la literatura (aprazível ao ouvido)" (p. 209).

Tendo isso em vista, na tentativa de contribuir para uma expansão do corpus das primeiras teorizações sobre tradução de modo a contemplar a reflexão produzida em línguas e culturas não hegemônicas, mesmo que europeias, como é o caso de Portugal, examinaremos aqui o mencionado texto de D. Duarte. Apresentamos ainda outro texto, "Das scripturas que el rey dom Afonso mandou tyrar en linguage e como fazia cada ano o aniversairio por seu padre" (Anexo II), escrito provavelmente por D. Pedro, conde de Barcelos (incluído na Crónica geral de Espanha de 1344), que explicita o ambicioso movimento de difusão científica pela via da tradução, empreendido por Afonso X, e que teve reflexos em Portugal, como 
será visto mais adiante. Apesar de bem distintos, os dois textos são bastante reveladores das práticas tradutórias e científicas da época, bem como das concepções e projetos de tradução vigentes. Ambas as reflexões, amparadas por argumentos históricos e examinados à luz do conhecimento produzido no âmbito da disciplina dos Estudos da Tradução, parecem constituir uma base consistente para que possamos propor a revisão de uma historiografia do pensamento sobre tradução, construída por organizadores de antologias estabelecidos no eixo Estados Unidos-Reino Unido-França e publicados por grandes editoras sediadas nesse mesmo eixo hegemônico.

\section{A tradução na Península Ibérica}

De maneira geral, podemos dizer que a tradução na Idade Média se preocupou com a transmissão da ciência antiga. Dos séculos VIII a X, houve um grande movimento tradutório na região de Bagdá, incentivado pela recém-chegada ao poder dinastia abássida. Sua principal característica foi a de verter para o árabe quase todas as obras gregas, contando com total apoio e patrocínio das elites. Para muitos (Gutas, 1998; Salama-Carr, 1990; Montgomery, 2000), esse acontecimento é de importância fundamental na história do pensamento.

Enquanto isso, excetuando-se a Península moura ${ }^{1}$, o acesso do mundo ocidental à ciência grega, em particular nos séculos VIII e IX (quando o conhecimento da língua grega já declinara bastante) restringia-se aos manuais e comentários compilados alguns séculos antes pelos enciclopedistas latinos. No século $\mathrm{X}$, entretanto, isso começou a mudar: alguns textos sobre o uso do astrolábio e outros assuntos foram traduzidos do árabe para o latim no sul da França, em decorrência do contato com os moçárabes da Espanha. Diversas traduções, do árabe para o latim, de obras sobre geometria e instrumentos astronômicos já eram feitas nessa época no Mosteiro de Santa Maria de Rípoli, no nordeste da Espanha (Grant, 1977: 
13-15), que era ao mesmo tempo biblioteca e centro cultural. O interesse pela ciência árabe se percebe também nas diversas viagens e escritos do professor de música e matemática Gerbert de Aurillac, que se torna, a partir de 1003, o papa Silvestre II. Ele adquiriu alguns tratados árabes que foram traduzidos para o latim.

Apesar desses movimentos pontuais, o grande episódio de tradução na Espanha só começa mesmo em meados do século XI e se estende até o XIII, inserido num contexto de efervescência cultural que, para muitos historiadores, foi como um Renascimento. Segundo Grant (1977: 14-16), do ponto de vista da história da ciência, só ocorreu algo semelhante, como já mencionamos, nos séculos VIII-X, com as traduções do grego para o árabe em Bagdá. Outro fator importante nesse contexto é o advento das universidades europeias (século XII) e das referências cada vez mais frequentes a tratados em grego ou árabe que só eram conhecidos pelo título, isto quando não eram totalmente desconhecidos. Os acadêmicos europeus começaram a se movimentar para ter acesso à herança intelectual do passado. Essas traduções do árabe e do grego para o latim atenderam à demanda por um novo tipo de conhecimento por parte dos próprios eruditos, que não queriam mais somente transmitir o que já conheciam, mas também aprender coisas novas (Gutas, 1998: 4).

A Espanha destacou-se nesse cenário, produzindo vários polos tradutórios, dos quais destacaremos três. O primeiro, centrado no século XII, caracterizou-se por um grande afluxo de traduções para o latim (tanto do árabe quanto do grego e também do hebraico), patrocinadas em grande medida pela Igreja e tendo como públicoalvo os próprios eruditos cristãos. $\mathrm{O}$ segundo pode ser associado ao grupo de trabalho em torno do filósofo, jurista e médico Averróis (1126-1198), que traduzia do grego para o árabe, revisava traduções prévias e, principalmente, fazia comentários - Averróis entrou para a história da filosofia ocidental como "o comentador" -, em busca de um novo horizonte de compreensão para a obra de Aristóteles. Inicialmente, houve apoio do califa de Córdoba, de 
quem Averróis cuidava e era conselheiro, mas suas opiniões acabaram atraindo suspeitas; ele se tornou persona non grata, teve seus livros queimados e caiu no ostracismo.

Por fim, o terceiro polo, já no século XIII, teve como figura de destaque o rei de Leão e Castela, Afonso X, o sábio (1221-1284), que patrocinou não só traduções do árabe para o castelhano, mas a pesquisa científica de maneira geral, a história e as artes. Decerto que não se visava propriamente um amplo público castelhano, até porque a maioria das pessoas era iletrada. Tratava-se mais de um projeto nacionalista, quiçá imperialista, que implicava uma negociação constante entre cristãos, judeus e muçulmanos, que conviviam pacificamente na corte em prol da recepção e divulgação da ciência greco-árabe (Ventura, 1985: 35-38). Foram produzidas várias pérolas da história da ciência nesse importante movimento centrado principalmente em Toledo, que se costuma identificar como Escola de Tradutores de Toledo (Delisle \& Woodsworth, 1998: 128). No entanto o termo "escola" vem sendo considerado cada vez mais inadequado para se aplicar a esse acontecimento, pois não se tratava de uma escola nem no sentido de formação de tradutores, nem no de uniformidade metodológica, cronológica, de domínio ou fontes. Para Santoyo (2004: 35), esse é um dos mitos mais duráveis da história da Espanha, pois nunca houve uma escola de tradutores de Toledo. A Espanha toda recebia tradutores de diversas partes da Europa, e a atividade tradutora estava espalhada por toda a Península. De maneira geral, a tradução era feita por indivíduos - muitos eram itinerantes - ou pequenos grupos sob patrocínio e diretrizes de um mecenas, como era o caso de D. Afonso.

É nesse contexto que se insere o texto que explicita o projeto tradutório de Afonso X, "Das scripturas que el rey dom Afonso mandou tyrar en linguagẽ e como fazia cada ano o aniversairio por seu padre", cuja íntegra se encontra no Anexo II e que foi extraído de uma das primeiras fontes da historiografia portuguesa, a já mencionada Crónica geral de Espanha de 1344: 
$\mathrm{Na}$ era de mil duzentos e noveeta e oito ãnos, quando andava o anno da naceça de Jesu Cristo en mil II LX, el rey dom Afonso, por [para] saber todallas scripturas, fezeas tornar de latin en linguagem. [...] Outrossi mandou tornar en linguagem todalas estorias da Bibria e os livros das artes das naturezas e da astronomya e muitos outros livros de desvayradas [diversas] sciençias e saberes. (Cintra, vol. IV, 1990: 507-8)

A amplitude dos temas vertidos do latim para o vernáculo a mando do rei fica bem patente no parágrafo introdutório desse texto que integra a Crónica, cuja autoria foi atribuída durante bastante tempo ao próprio Afonso X, e que posteriormente teria sido traduzida ou mandada traduzir para o português por D. Dinis. Todavia, no século XX, os manuscritos começaram a ser analisados linguística, histórica e literariamente, não havendo mais motivos para se supor que não tenham sido escritos originalmente em português. Segundo Cintra (1990, vol. I: LXXVIII), “a crônica de 1344 se deve a um português [...] um discípulo português dos historiógrafos castelhanos da escola de Afonso X", provavelmente D. Pedro, o conde de Barcelos, filho de D. Dinis e organizador do Livro das linhagens. Os argumentos são cuidadosamente apresentados por Cintra no primeiro volume da edição crítica da Crónica, e se resumem da seguinte maneira: 1) as fontes da Crónica e do Livro das linhagens são as mesmas, exceto pela Crónica do mouro Rasis, incluída na Crónica geral de Espanha, mas; 2) decerto o conde de Barcelos conhecia essa crônica, já que fora seu sogro quem a traduzira, a mando de D. Dinis; 3) D. Pedro esteve na Espanha de 1317 a 1320, e provavelmente entrou em contato com a escola de Afonso X e com as suas fontes; 4) por volta de 1344, D. Pedro tinha a tranquilidade e a capacidade literária necessárias para uma empreitada desse porte (Cintra, 1990: CLXXXIX-CLXC).

Com base nessa empreitada, Cintra faz uma reflexão importante sobre a questão da autoria nesse período, além de apresentar um 
paralelo entre as práticas de tradução, compilação e redação levadas a cabo por D. Pedro e seu bisavô, Afonso X:

D. Pedro é autor do Livro das linhagens [e também da Crónica geral de Espanha] pouco mais ou menos no mesmo sentido em que seu bisavô, Afonso, o Sábio, o é de suas obras. Dirige a compilação das fontes, indica como hão de ser utilizadas, manda-as traduzir quando necessário e encarrega os seus colaboradores de redigir a obra, segundo as suas orientações. Ele próprio revê e aperfeiçoa o conjunto, uma vez redigido. (Cintra, 1990: CLXXXIII)

É a figura do autor-coordenador que, guardadas as devidas proporções, equivale às edições atuais de grandes dicionários, como é o caso dos nossos Aurélio e Houaiss, que são organizados e efetivados segundo a orientação estabelecida por seus autores. O sentido de autoria aqui tem um aspecto coletivo, como na Bagdá de Hunayn ibn Ishaq (século IX), que foi o mais renomado tradutor árabe. Ademais, de maneira geral, a autoria não era prioridade na Idade Média, e a produção textual baseava-se na imitação de modelos autorizados, sendo os textos traduzidos, copiados e comentados sem a preocupação de registrar a origem ou o autor do texto. O parâmetro da originalidade só aparece com a modernidade.

A conexão intelectual entre Espanha e Portugal fica evidente, como vimos na Crónica geral de Espanha, já que Afonso X, patrono das atividades tradutórias em Toledo, é uma das figuras de destaque na história da ciência em Portugal, pois presenteou seu neto, D. Dinis, rei de Portugal que em 1288 fundou a primeira universidade portuguesa, com boa parte de suas obras científicas. Além disso, mais do que parecidos, os idiomas português e espanhol compartilham de uma mesma fonte: a deriva do latim imperial em proto-romance (a partir do século VIII), que, em Portugal, gradativamente vai dar origem ao galego-português e, na Espanha, ao castelhano e ao leonês (Teyssier, 1997: 13). Apesar de, no século 
XII, essas línguas estarem começando um processo de separação, decerto continuou havendo intercâmbio por conta de uma história comum, da proximidade geográfica, entre outros fatores. Isso ainda é evidente na produção escrita dos anos quinhentistas, tendo em vista que quem escrevia em português, escrevia em espanhol e latim também (como foi o caso do matemático Pedro Nunes e de Camões). Acrescente-se a isso a União Ibérica, que ocorreu quando as duas línguas estavam começando um movimento de autonomia (produção de gramáticas, por exemplo). Nesse período, havia também o "retorno" ao latim, por conta do Humanismo, marcando ainda mais o trilinguismo do erudito português. Sobre isso, A. A. Gonçalves Rodrigues, na introdução do seu A tradução em Portugal, diz o seguinte:

O português é reconhecidamente um poliglota nato, e o escol dirigente, educado à sombra da Igreja ou ao seu serviço, vivia mentalmente no mundo da cultura latina medieval. [...] Tanto mais importante como fonte de cultura e de espiritualidade foi o conhecimento generalizado do castelhano em Portugal durante três séculos. [...] Daí que o nosso escol fosse educado na familiaridade com textos escritos em língua que para compreender não precisava de traduzir. [...] Além do latim, o castelhano serviu durante décadas como veículo obrigatório pelo qual se alimentava a sensibilidade e a cultura do escol português, eclesiástico ou laico. (Rodrigues, 1992: 27-28)

\section{Teorização pioneira em língua portuguesa}

Como vimos, a tradução teve um papel importante nos primórdios da historiografia portuguesa que, entre outras fontes, deve-se à Crónica do mouro Rasis, traduzida do árabe para o português. ${ }^{2}$ 
Vimos também que as traduções grego-árabe-hebraico-latim-vernáculos foram patrocinadas por elites e governos, como foi o caso dos reis D. Afonso e D. Dinis, do conde de Barcelos, da Igreja e dos califas de Bagdá e Córdoba, com o propósito de fortalecer projetos nacionais, atender a estratégias político-pedagógicas ou simplesmente transmitir o conhecimento. Além disso, as traduções não eram feitas por tradutores profissionais, como hoje em dia, mas pelos próprios acadêmicos, que, muitas vezes, chegavam ao ponto de cruzar continentes em busca dos textos.

Podemos imaginar, então, um cenário em que ideias, textos e saberes transitam de uma língua para a outra e de um lugar para o outro, num movimento de intercâmbio cultural assaz enriquecedor, o que não significa que não houvesse tensões e hesitações, em função de interesses nacionais, religiosos ou comerciais. Também podemos imaginar que houvesse intelectuais altruístas, forças de relevo num acontecimento desse tipo, mas a abundância de traduções da maneira que houve não pode ser atribuída a indivíduos isolados, e sim a forças ativas diversas, como o interesse das elites que deram o apoio necessário para que isso acontecesse. Por outro lado, havia também forças reativas, como a Inquisição e os reis católicos, que perseguiam as "práticas judaizantes", dentre as quais várias ciências. Como eram esses próprios "praticantes" que, em grande medida, faziam as traduções, diversos tradutores também foram perseguidos.

Foi nesse contexto que D. Duarte, rei de Portugal entre 1433 e 1438 , elaborou as reflexões registradas no texto "Da maneira pera bem tornar algũma leitura em nossa linguagem", que é o capítulo LRIX do Leal conselheiro, obra de sua autoria, concebida como um tratado sobre ética e moral dirigido aos membros da corte. ${ }^{3}$ Acredita-se que o rei a tenha compilado por volta de 1438, próximo a sua morte. Trata-se, portanto, de um texto do período arcaico médio da língua portuguesa, que abrange do século XIV à primeira metade do XVI (Bechara, 1985).

D. Duarte fez traduções do latim - bem como seu irmão, o infante D. Pedro - e também patrocinou Fernão Lopes, grande 
cronista do período arcaico da língua portuguesa, que escreveu a Crónica de D. João I, a Crónica de D. Pedro e a Crónica de D. Fernando. Vale lembrar que esses filhos de D. João I, fundador da dinastia de Avis, além de tradutores, favoreceram também a empreitada tradutória na corte, patrocinando, entre outros, Vasco Fernandes de Lucena, João Verba e Alfonso de Cartagena. Segundo Sebastião Tavares de Pinho, em seu artigo "D. Pedro e a 'escola' de tradutores da corte de Avis", é possível admitir que havia "outros anónimos a exercer a actividade de tradutores no âmbito e sob patrocínio dos príncipes de Avis” (Pinho, 1993: 151).

Podemos dizer que "Da maneira pera bem tornar..." apresenta inicialmente cinco regras para se fazer uma boa tradução para o português, como anuncia o título, seguidas de comentários sobre dois exemplos de traduções feitas pelo autor: uma oração em latim do século X, intitulada "Justo Juiz Jesu Cristo", e um fragmento de capítulo do Livro dos Stabelicimentos de Sam Joham Cassiano (D. Duarte, 1998 [1435-1438]: 362-366).

As cinco regras formuladas por D. Duarte podem ser assim resumidas:

1. Conhecer bem o material que se vai traduzir e não mudar, acrescentar ou excluir nada;

2. Não usar latinismos nem estrangeirismos, apenas o português mais próximo do que costumamos falar;

3. Traduzir ao pé da letra, usando as palavras portuguesas correspondentes às latinas, porque isso faz muita diferença para o bom entendimento;

4. Não usar palavras obscenas;

5. Escrever claramente, da forma mais agradável possível e também de maneira concisa sempre que necessário - e para isso, é importante dominar a paragrafação e pontuação.

Trata-se, portanto, de um texto tipicamente normativo, pois elabora regras para o bem traduzir e dá muitas instruções para o 
tradutor, insistindo em restringir o nível de intervenção ao mínimo: não alterar em nada a macroestrutura do texto, evitando acréscimos e omissões, e buscar o equivalente em língua portuguesa mais próximo da palavra latina - onde estiver em latim scorregar não traduzir por afastar, "e assi em outras semelhantes" (p. 362).

Por outro lado, abre-se uma exceção à regra de não mudar nada quando o texto trouxer "palavras que segundo o nosso custume de falar sejam havidas por desonestas" (ibid.), ou seja, se houver termos ofensivos no original, o tradutor deve intervir e suprimi-los, substituindo-os por outros mais aceitáveis.

Além de oferecer esse receituário, D. Duarte, o eloquente, também faz alusão a uma prática tradutória a quatro mãos, na qual uma pessoa traduz oralmente a partir do latim enquanto a outra escreve, parecendo sugerir que o trabalho feito conjuntamente por duas pessoas seja revisado inteiramente por uma só pessoa: "Se ũu razoar, tornando de latim em linguagen, e outro screver, achará melhoria de todo juntamente per ũu seer feito" (ibid.).

Em seguida a esse primeiro parágrafo com as regras e o comentário mencionado acima, o monarca-tradutor apresenta os dois exemplos de trabalhos feitos, e logo se pode observar uma contradição. No primeiro exemplo, a oração em versos "Justo Juiz Jesu Cristo", já no segundo verso D. Duarte quebra a segunda regra, a de não usar latinismos, ao se referir ao "Justo juiz Jesu Christo" como "Rei dos Rex e boo Senhor", empregando, portanto, a palavra latina rex.

Também é interessante notar que, ao apresentar o segundo exemplo de tradução, um fragmento de capítulo do Livro dos Stabelicimentos, D. Duarte elabora uma reflexão sobre a recepção do texto pelos seus pares. Ele diz que fez uma tradução ao pé da letra, mas que alguns eruditos não aprovaram, por ter sido escrita à maneira latina:

E traladei do livro dos Stabelicimentos de Sam Joham Cassiano por exempro esta parte de ũu capitolo ajuso scripto 
ao pee da letera, que chamam os leterados "a contexto", o qual a algũus nom muito praz, por seer scripto na maneira latinada. E queriam que se tirasse a sentença posta em mais geeral maneira de falar. E outros dizem que bem lhes parece (ibid.: 365).

De acordo com esses críticos, o livro deveria ter sido traduzido de uma maneira mais próxima do que se costuma falar (segunda regra) e não "a contexto". Por outro lado, outras pessoas consideraram boa a tradução. Diante dessa controvérsia, D. Duarte oferece uma sugestão: "Por em, quando mandardes tornar algũa leitura de latim em nossa linguagem, a maneira que mais vos prouver mandae que tenha aquel que delo tever cárrego" (ibid.), ou seja, quem encomendar a tradução deve dizer ao tradutor como quer que o trabalho seja feito. Aqui é interessante notar a referência a uma prática (que podemos supor) comum de "mandar traduzir", ou seja, "um contributo para a criação, à volta da corte de Avis, de um clima particularmente favorável ao empreendimento de traduções de obras latinas" (Pinho, 1993: 153).

Como registra Robinson (1997: 60), as reflexões de D. Duarte são ligeiramente posteriores às desenvolvidas pelo humanista italiano Leonardo Bruni Aretino (1374-1444) em De interpretatione recta (1424/26), apresentado originalmente como um paratexto da sua tradução da Ethica Nicomachea (1414/18), de Aristóteles, e “é considerado o primeiro tratado moderno em apresentar de forma independente reflexões sobre a tarefa de traduzir, em especial sobre a tradução literária" (Furlan, 2006: 49). Por outro lado, pode-se considerar "Da maneira pera bem tornar algũma leitura em nossa linguagem" um texto bastante pioneiro, visto que precede em mais de cem anos o clássico La manière de bien traduire d'une langue em autre, de Etienne Dolet (1509-1546), publicado em 1540, que também estabelece cinco princípios para o tradutor e é considerado por vários autores uma das primeiras tentativas de sistematizar o pensamento teórico sobre tradução. Além dos contemporâneos 
Munday (2001: 24-25) e Bassnett (2002 [1980]: 54), Nida já havia destacado o papel primordial do tradutor francês ao afirmar que, apesar da grande importância de Lutero nesse campo, "o crédito pela primeira formulação de uma teoria da tradução pertence a Etienne Dolet, [que] publicou em 1540 uma curta mas incomparável declaração de princípios sobre a tradução"4 (1964: 15).

São estes, resumidamente, os princípios de Dolet (Munday, 2001: 26):

1. O tradutor deve entender perfeitamente o sentido e o material do autor original, embora tenha a liberdade de esclarecer o que estiver obscuro.

2. O tradutor deve ter total conhecimento tanto da língua fonte como da língua meta, de modo a não diminuir a grandiosidade da língua.

3. O tradutor deve evitar traduzir palavra por palavra.

4. O tradutor deve evitar formas latinas e pouco usuais.

5. O tradutor deve escolher e ordenar as palavras de modo eloquente, para evitar construções canhestras.

As reflexões de D. Duarte e Dolet têm alguns pontos convergentes, além do número idêntico de regras: (i) de caráter prescritivo, pertencem a um gênero que, segundo Rener (1989: 261-262), foi iniciado por S. Jerônimo em sua famosa carta a Pamáquio, Ad Pammachium de optimo genere interpretandi ["A Pamáquio, o melhor método de tradução"], no qual são formuladas instruções práticas a respeito de aspectos importantes da tradução; (ii) recomendam que sejam evitados latinismos e palavras pouco familiares; (iii) preconizam uma compreensão total do material a ser traduzido e uma redação clara e esmerada.

Há, também, divergências, que se fazem notar em relação a dois aspectos: (i) enquanto Dolet concede ao tradutor a liberdade de esclarecer o que estiver obscuro, D. Duarte adverte que não se deve mudar, acrescentar ou suprimir nada, a não ser com o objeti- 
vo de evitar termos obscenos; (ii) para Dolet, o tradutor deve evitar traduzir palavra por palavra, ao passo que D. Duarte é a favor dessa estratégia, "porque isso faz muita diferença para o bom entendimento" (regra de número 3, acima), embora abra espaço para avaliações caso a caso, como já mencionado.

No artigo "Brevíssima história da teoria da tradução no Ocidente - Renascimento" (2004), Furlan cita como uma das características da história da tradução renascentista "o desenvolvimento de reflexões teóricas sobre a prática tradutora, que se apresentam geralmente sob a forma de pequenos textos, cartas, introduções, tratados etc." (p. 21). O texto de D. Duarte, que precede o de Dolet em mais de cem anos, parece encaixar-se nessa categoria, respaldado na vivência como tradutor e agente de patronagem de seu autor. É importante, ainda, por retratar as concepções e métodos de tradução existentes à época. No entanto, as referências a esses preceitos e comentários na literatura historiográfica da tradução são raras e até imprecisas. Para o historiador Frederick Rener, por exemplo, a ars interpretandi de D. Duarte foi produzida "no século XV, alguns anos antes de Dolet" (1989: 262), reduzindo bastante o período de um século que separa as duas reflexões.

\section{Considerações finais}

Embora Munday (2001) e Bassnett (1980) já considerem os princípios de Dolet como uma tentativa de sistematização, Steiner os denomina de "reflexões empíricas". Ele os incluiu no primeiro dos quatro períodos em que divide a literatura sobre a teoria, a prática e a história da tradução (1975: 236-237), caracterizado por reflexões empíricas desenvolvidas por tradutores a respeito de suas próprias traduções, particularmente em prefácios ou introduções. No entanto, para o próprio Steiner (1975: 236), De interpretatione recta, de Leonardo Bruni, é um importante texto teórico desse primeiro período. 
Consequentemente, tendo em vista os seguintes aspectos:

i. a similaridade de função entre as determinações de D. Duarte e Dolet, voltadas para questões de poética tradutória;

ii. o fato de serem o francês Dolet e o inglês George Chapman (c. 1559-1634) considerados pelos historiadores da tradução os primeiros a formularem uma teoria da tradução (Bassnett, 1980: 54), seguidos pelos igualmente ingleses John Dryden (1631-1700) e Alexander Fraser Tytler (1747-1813), cuja obra Essay on the principles of translation, de 1792, marca o final do primeiro período postulado por Steiner;

iii. a hegemonia das culturas de língua inglesa e francesa, que propiciam e viabilizam o desenvolvimento de estudos e pesquisas em diversas áreas, inclusive nos Estudos da Tradução, e que concentram a maioria das grandes editoras, que publicam essas pesquisas e as divulgam internacionalmente,

propomos que os atuais cânones da teoria da tradução - promovidos em geral por autores e publicações de línguas e culturas hegemônicas - sejam revistos de modo a incluir reflexões bastante pioneiras sobre a práxis tradutória por parte de autores como D. Duarte, pensamento este coerente com o prescritivismo das primeiras teorizações e com as preocupações com questões de fidelidade e literalidade que predominavam no cenário intelectual e literário do Renascimento. Acreditamos que gestos contra-hegemônicos como o aqui proposto são cada vez mais necessários, para que se possa repensar os valores, crenças, ideias e cânones que vêm sendo consolidados e transmitidos por aqueles que exercem o poder e a autoridade de construir as narrativas reconhecidas como verídicas. 


\section{Notas}

1. Em 750 , com a chegada ao poder da dinastia dos abássidas, os omíadas foram massacrados, exceto Abn al-Rahman, que fugiu para a Espanha, onde organizou o emirado de Córdoba (756). Em 912, Córdoba transformou-se em califado. Para mais informações, cf. Lewis, 1983.

2. Só para mapear um pouco a história de Portugal, os romanos chegaram à Península em 218 a.C. Nos séculos V, VI e VII, invasores germânicos romperam a unidade romana. Em 711, muçulmanos invadem a região e, depois da chamada Reconquista, no século XII, finalmente se instaura o reino independente de Portugal. Cf. Marques, 2006.

3. O texto só foi descoberto em 1804, na Biblioteca Nacional de Paris, datado por especialistas e publicado pela primeira vez na década de 1940.

4. Tradução nossa, assim como as demais citações extraídas de referências em língua estrangeira.

\section{Bibliografia}

BALLARD, Michel. De Cicéron à Benjamin - traducteurs, traductions, réflexions. Lille: PUL, 1992.

BASSNETT, Susan. Translation studies. London/New York: Routledge, 1980.

BECHARA, Evanildo. As fases históricas da língua portuguesa. Niterói: UFF, 1985 (inédito). 
CINTRA, Luís F. Lindley (Org.) Crónica geral de Espanha de 1344. Lisboa: Imprensa Nacional - Casa da Moeda - Academia Portuguesa de História, 1990 (Edição crítica em 4 volumes).

DELISLE, Jean; WOODSWORTH, Judith (Orgs.) Os tradutores na história. Tradução de Sérgio Bath. São Paulo: Editora Ática, 1998.

D. DUARTE. Leal conselheiro. Edição crítica, introdução e notas de Maria Helena Lopes de Castro. Lisboa: Imprensa Nacional - Casa da Moeda, 1998 [14351438].

GRANT, Edward. Physical science in the middle ages. Cambridge University Press, 1977.

GUTAS, Dimitri. Greek thought, arabic culture. London/New York: Routledge, 1998.

FURLAN, Mauri. "Apresentação a De recta interpretatione, de Leonardo Bruni Aretino”. Em: Clássicos da Teoria da Tradução. Antologia bilíngue, vol. 4, Renascimento. Florianópolis: NUPLITT, 2006.

. "Brevíssima história da teoria da tradução no Ocidente III. Final da Idade Média e o Renascimento". Cadernos de Tradução, PGET/UFSC, n. XIII, 2004/1, 9-25.

LEWIS, Bernard. Os árabes na história. Tradução de Maria do Rosário Quintela. Lisboa: Editorial Estampa, 1983.

MARQUES, A. H. de Oliveira. Breve história de Portugal. Lisboa: Editorial Presença, 2006.

MONTGOMERY, Scott L. Science in translation: movements of knowledge through cultures and time. Chicago: University of Chicago Press, 2000.

MUNDAY, Jeremy. Introducing Translation Studies: theories and applications. London/New York: Routledge, 2001. 
NIDA, Eugene. Toward a science of translation. Leiden: Brill, 1964.

PAIS, Carlos Castilho. Teoria diacrónica da tradução portuguesa: antologia (séculos XV-XX). Lisboa: Universidade Aberta, 1997.

PINHO, Sebastião Tavares de. "D. Pedro e a 'escola' de tradutores da corte de Avis”. In: Biblos, v.LXIX, 1993, p. 129-153.

PINILLA, J. A. Sabio; SÁNCHEZ, M. M. Fernandez. O discurso sobre a tradução em Portugal. Lisboa: Edições Colibri, 1998.

PINILlA, J. A. Sabio; VAlENCIA, M. Dolores. Seis estudios sobre la traducción en los siglos XVI y XVII (España, Francia, Italia, Portugal). Granada: Editorial Comares, 2003.

RENER, Frederick M. Interpretatio - language and translation from Cicero to Tytler. Amsterdam/Atlanta: Rodopi, 1989.

ROBINSON, Douglas (Org.) Western translation theory from Herodotus to Nietzche. Manchester: St. Jerome, 1997.

RODRIGUES, António Gonçalves. A tradução em Portugal. Lisboa: Imprensa Nacional - Casa da Moeda, 1992.

SALAMA-CARR, Myriam. La traduction a l'époque Abbasside. Paris: Didier Érudition, 1990.

SANTOYO, Julio-César. "La Edad Media". In: LAFARGA, Francisco; PEGENAUTE, Luis (Orgs.) Historia de la traducción en España. Salamanca: Editorial Ambos Mundos, 2004, p. 23-174.

STEINER, George. After Babel. Aspects of language and translation. Oxford: Oxford UP, 1975.

TEYSSIER, Paul. História da língua portuguesa. Tradução de Celso Cunha. São Paulo: Martins Fontes, 1997. 
VENTURA, Manuel Sousa. Vida e obra de Pedro Nunes. Lisboa: Instituto de Cultura e Língua Portuguesa, 1985 (Biblioteca Breve). 